\title{
EDITORIAL NOTICE
}

"Notes and Comment"

Beginning with this issue, PERCEPTION \& PSYCHOPHYSICS introduces a new section-"Notes and Comment."

The content and nature of this section is not exhaustively definable at present. However, the major content will consist of reader comments on articles published in PERCEPTION \& PSYCHOPHYSICS and in some instances other joumals that cover the same research areas. While criticisms of methodology and interpretation are valuable and informative, emphasis will be placed on the constructive role of the communication. Reports of original observations or data relevant to the interpretation of articles that have appeared in the journal will be considered appropriate. However, these reports should be informal in style and not constitute a "brief research report." This latter form of communication is more appropriate for The Bulletin of the Psychonomic Society, and "Notes and Comment" is not intended to overlap with The Bulletin.

Authors must assume the major responsibility for the accuracy and validity of their contributions, since the very nature of this section precludes rigorous editorial review for scientific merit. While the style should be informal, the writing must be clear and concise. As always, we must husband joumal space. Contributions should be submitted in triplicate. Since the contents of "Notes and Comment" will be listed by author and title on the cover of the journal, a short title for the contribution must be provided by the author. As with manuscripts submitted as regular articles, contributions to "Notes and Comment" should be sent to The Editor, Charles W. Eriksen, Psychology Building, University of Illinois, Champaign, Illinois 61820. 